\title{
NARRAR EL INFIERNO VERDE. SOBRE LA NOVELA LATINOAMERICANA DE PLANTACIÓN*
}

\author{
TO WRITE THE GREEN HELL. ON THE LATIN AMERICAN \\ PLANTATION NOVEL
}

Jorge URrutia

Catedrático Emérito

Universidad Carlos III de Madrid, Madrid, España

\begin{abstract}
Resumen: En este artículo se reflexiona sobre el realismo literario y la noción de testimonio para introducir un tema característico de la literatura latinoamericana: la novela de plantación que, en este caso, se limita a los yerbales de hierba mate. Busca distinguir la novela de la vida y basa su concepto de lo literario en la construcción de modelos de composición a partir de la importancia de la tradición cultural.
\end{abstract}

Palabras clave: Realismo, testimonio, novela de plantación, veracidad literaria.

\begin{abstract}
This article reflects on literary realism and the notion of testimony to introduce a characteristic theme on Latin American literature: The plantation novel that, in this case, is limited to the hierba mate grass crops. It aims to distinguish novel from life and bases its literary concept in the construction of composition models from the importance of cultural tradition.
\end{abstract}

Keywords: Realism, testimony, plantation novel, literary veracity.

Recibido: 06.03.2018. Aceptado: 20.05.2018.

$\mathrm{E}$ N 1935 EL ESCRITOR costarricense José Marín Cañas (1904-1980) publicó una novela que explora, como otras coetáneas, las posibilidades del vanguardismo para expresar "la sensación de vivir una época de trastrueque y desbarajuste, de "caducidad de las formas de vida, las relaciones, las

* Este trabajo se redactó en el marco del proyecto "Espacios públicos del saber en la encrucijada del siglo XIX al XX”, integrado en el Ministerio de Economía y Competitividad del Gobierno del Reino de España, con la clave HAR2014-57245-P. 
creencias y los valores tradicionales" (Quesada Soto, 2008: 69 y ss.) $)^{1}$. Es decir, se interesaba en denunciar la estructura social de su tiempo por medio de una escritura que fuera ya en sí ruptura con los modos del realismo canónico. En aquellas fechas los escritores habían superado lo destructor de las vanguardias y buscaban prácticas capaces, como el propio surrealismo, de construir nuevas relaciones significativas.

Marín Cañas sabía que la literatura radica, precisamente, en el cruce entre lo existente y una expresión descubridora, lo que conlleva una dialéctica fundamental entre el espejo y el modo de llevarlo, si se me permite una ironía sobre la famosa reflexión stendhaliana de Le rouge et le noir [1830].

Stendhal encabeza el capítulo XIII de la primera parte de su famosa novela, con una cita que se ha hecho lugar común en la crítica literaria: "Una novela: es un espejo que paseamos a lo largo de un camino". La afirmación se acepta repetidamente como defensa de un realismo que refleje lo que ocurre, como si la construcción lingüística no obligase a una transformación similar a aquella que se produce, en el lienzo o en la fotografía, al pasar de las tres dimensiones a las dos del plano.

Stendhal toma la cita de un escritor del siglo XVIII hoy olvidado, el abate Vichard de Saint-Réal, quien fue autor, entre otras cosas, de un librito de tema histórico, Conjurations des espagnols contre la république de Venise en l'année 1618, publicado en 1683. Éste concluye, a su vez, con una referencia al militar e historiador renacentista François de la Noüe, quien habría afirmado: "cuando algún hecho ha sido descrito en verdad y con sus circunstancias, aunque no se haya conseguido más que a la mitad, puede siempre extraerse algún fruto" (1683: 177). La afirmación podría cuestionar la exactitud de lo que entendemos por testimonio o bien, puesto que la hace suya Saint-Réal, el autor de la frase citada en El rojo y el negro, aceptar

${ }^{1}$ Utilizo, según la norma de la revista, el sistema de referencia de la American Psychological Association, que se ha venido imponiendo, por influencia de las publicaciones técnicas norteamericanas, pese a las confusiones que ocasiona en los temas humanísticos. Indico, cuando es posible, la fecha primera de publicación (en Humanidades ésta resulta muy significativa), aunque en la bibliografía exprese la edición utilizada, a la que siempre se refieren los números de páginas. Cuando sólo busco recordar al lector la fecha original de publicación de alguna obra que no necesita aparecer en la bibliografía final, empleo paréntesis cuadrados, también denominados corchetes. Para que el lector sitúe cómodamente a los escritores fundamentales de mi trabajo en sus relaciones vitales, indico entre paréntesis, tras el nombre, las fechas de nacimiento y, en su caso, muerte. 
que el espejo pueda ser, a la manera de Ramón del Valle-Inclán en Luces de Bohemia, cóncavo o convexo.

Es fácil comprender que traigo a colación El infierno verde (la guerra del Chaco), que es así como se llama el libro de Marín Cañas, por la coincidencia de su título con el de mi trabajo pero, además, porque esta novela es buen ejemplo de la problemática que conlleva el realismo literario, máxime cuando ya se habían manifestado las vanguardias literarias históricas. Ya sea normal, cóncavo o convexo, todo espejo paseado por el borde del camino muestra las gentes, y las relaciones que establecen entre sí, en una organización social precisa y en unos espacios que, como el ángulo y el reflejo, nunca resultan inocentes. La diferencia radica en el tipo de espejo que se lleva, en su orientación y en la imagen resultante.

\section{El testimonio}

El realismo del siglo XIX ya descubrió que la literatura no tenía por qué prescindir de aquellas capas sociales que hasta entonces sólo habían sido comparsas de los protagonistas. Tras Geneviève, histoire d'une servante [1863], de Lamartine, los hermanos Goncourt, en el prólogo a Germinie Lacerteux [1865], denuncian que existen "aún para el escritor y para el lector clases indignas, desdichas demasiado bajas, dramas demasiado groseros y catástrofes de un terror muy poco noble" (Urrutia, 2015: 133 y ss). Llama la atención que, curiosamente, a Émile Zola no le llamó la atención que la protagonista de la novela de los Goncourt fuera una criada, tal vez porque conocía la obra de Lamartine; no comenta, por ejemplo, el famoso prólogo (Zola, 1866). El estudio clásico sobre Germinie Lacerteux es el de Auerbach (1946).

Descubrir para la novela al trabajador y, más tarde, al proletario traería sus consecuencias: obligó a describir el medio en el que su vida transcurre, descubrir sus costumbres, sus virtudes y sus vicios, analizar las relaciones que lo ligan con los propietarios y con los responsables intermedios, exponer las condiciones de trabajo... Si Balzac se ocupó de la decadencia de la nobleza bajo el empuje de una burguesía abrumadora, si Eça de Queirós vio los pies de barro de los nuevos comerciantes ciudadanos, si Pérez Galdós se preocupó por la pequeña burguesía funcionarial, Émile Zola quiso retratar 
el poder económico y político de la nueva clase burguesa y sus efectos sobre el proletariado e, incluso, sobre lo que se llamaría el "lumpen-proletariat". Más allá del determinismo, en Hispanoamérica, desde La bolsa [1898], de Julián Martel, a El socio [1928], de Jenaro Prieto, el juego de la burguesía económica ha sido tema novelesco.

Cuestión distinta es la equiparación, cuando no confusión, en la novela latinoamericana del siglo XX, entre el proletario y el indígena, ya sea éste obrero de las plantaciones o soldado enfrentado a los obreros, siempre comprometidos uno y otro, arrastrados por las circunstancias y los intereses de las multinacionales.

Un pobre indio -leemos en la novela de Marín Cañas-, achatado y esclavo, carne de rabenque, espíritu de derrota, que habrá pasado su vida con la espalda hecha un arco sobre la tierra seca, y que hoy muere en defensa de esa tierra que no le dio ni sombra. [...] Qué sabe este indio de los oleoductos que traerían pingües ganancias para la Standard Oil de Santa Cruz, si los hacen llegar hasta la cuna del río Paraguay (Martín Cañas, 1935: 102).

La literatura realista o naturalista que pretendía ser reflejo más o menos exacto y científico de la sociedad, empezó a entenderse como denuncia; ésta exigió la prueba fehaciente de su verdad y surgió el concepto de testimonio ${ }^{2}$. El testimonio parece ligado al relato de las guerras aunque ni Victor Hugo (1802-1885), ni Erckmann-Chatrian (1822-1899 y 1826-1890), ni Émile Zola (1840-1902), ni el mismo Benito Pérez Galdós (1843-1920), ni Paul y Víctor Marguerite (1860-1918 y 1866-1942), por citar algunos autores de novelas testimoniales, fueran combatientes. Curiosamente, es la Baronesa Bertha von Suttner (1843-1914), autora de la novela pacifista Adiós a las armas [1889], la que parece más próxima a lo descrito en sus páginas.

Fue luego la primera guerra mundial la que despertó la necesidad de una literatura de la experiencia vivida, sin que falte en ella el sentimiento de

${ }^{2} \mathrm{El}$ concepto de testimonio cuenta con una amplia bibliografía de corte filosófico que no debe desconocerse y resulta muy discutido. No puedo entretenerme aquí en él. Le dediqué algunas páginas en mi libro Juguetes de un dios frío (ya citado), volveré con más detalle en un ensayo próximo y conviene leer el libro de Beatriz Sarlo Tiempo pasado. Cultura de la memoria y giro subjetivo. Una discusión, que constituye un excelente resumen y una puesta a punto. 
clase. Pero es que la revolución soviética, la fermentación anterior a 1917 y los efectos inmediatos fueron coetáneos de aquella Gran Guerra. Se empieza a imponer entonces la idea de una necesaria literatura testimonial de la que el ejemplo más conocido es El fuego [1916], de Henri Barbusse (1873-1935). El concepto fue descrito por Jean Norton Cru (1879-1949) en un libro de 1930, Du témoignage. Insiste este estudioso, sin embargo, y es muy importante, en que el testigo olvida. Si se conformase con la pérdida del recuerdo exacto no sería demasiado grave, pero sucede que la memoria lo engaña y, a la vez que olvida sin percatarse siempre de ello, lleva a cabo una creación que nunca es acorde con la exactitud de los hechos. Tales afirmaciones de quien tan detenidamente estudió el fenómeno del testimonio sirven para poner sobre el tapete la realidad de una escritura que, después, se ha querido ver por algunos como característica casi exclusiva de la literatura latinoamericana, tanto temática como formalmente. Óscar Collazos (1942-2015) se atrevió a ligar el testimonio a una suerte de noción unitaria continental. El viejo e irrealizado sueño de Simón Bolívar resurgiría de la mano de unos caracteres literarios con valor identitario. Por eso entendía en un ensayo de 1969 el crítico y narrador colombiano, afincado entonces en Cuba, que era preciso el "acercamiento a una manera de concebir la literatura como ejercicio autónomo del contexto cultural y político” de Latinoamérica, que él veía necesariamente testimonial (Collazos et alii, 1970) ${ }^{3}$.

Erckmann-Chatrian, en una novela en torno a la derrota definitiva de Napoléon, y titulada precisamente Waterloo [1865], ya aclararon que

cuando se habla de una batalla como ésa, hay que explicarlo todo; pero las cosas que uno ha visto por sí mismo son lo principal; puede uno decir: Yo lo he visto. Y lo demás lo he sabido tan sólo por personas honradas incapaces de mentir (1865: 169).

\footnotetext{
${ }^{3}$ Resulta ocioso recordar aquí, además de la literatura testimonial emanada de las dos guerras mundiales, la escrita a partir de la experiencia en los campos nazis; el problema de estos testimonios lo estudia Annette Wieviorka (1998). Probablemente el mayor interés desde el punto de vista de la técnica literaria esté hoy en la obra de Svetlana Alexiévich y libros como Los muchachos de zinc [1991] y otros libros; la de Gitta Sereny, Into that Darkness [1974] o Cries unheard. The History of Mary Bell [1989]; y más modernamente, un libro como Laëtitia ou la fin des hommes [2016], de Ivan Jablonka.
} 
Por lo tanto el testigo no lo suele ser de la totalidad de lo sucedido y la aceptación de su discurso como documento histórico presenta, pese a las insistencias posmodernas, graves dudas (como el trabajo jurídico, por otra parte, demuestra). Si toda novela realista es fruto de una selección de la realidad, el testimonio reduce aún más el panorama y, sobre todo, fija un sujeto del enunciado peculiar, doblemente ideologizado y, por ello, más producto del espejo cóncavo que del plano.

El novelista siente la necesidad de una tabla de salvación teórica y ésta viene a ser la de los géneros periodísticos y, especialmente, la crónica. El periodismo aspira, al menos teóricamente, y aunque ya sabemos de su imprescindible parcialidad, a la asepsia informativa. Surge así una escritura que distingue con dificultad la crónica (cuyo sentido está en la fragmentación y en la provisionalidad) de la ficción novelesca (cuyo afán es el cierre y la permanencia). Esta inquietud sobre los límites de la literatura se aprecia en la novela de José Marín Cañas El infierno verde, que he venido citando 4 .

\section{La tradición}

Conviene aquí hacer una consideración que suele olvidarse. La literatura es compañera de vida, pero no es la vida. Si confundimos ambos planos de comprensión estaremos, como se dice en Chile, "más perdidos que el teniente Bello" 5 . Nuestros actos se integran en una suerte de gramática factual que hemos aprendido y desarrollado; a su vez, las obras literarias se sitúan en una tradición que condiciona, a favor o en contra, toda escritura. Desde el punto de vista literario, lo importante no es, por ejemplo, haberse sorprendido por la grandiosidad de la naturaleza, sino cómo ésta y la sorpresa se describen y

${ }^{4}$ Ya Álvaro Quesada Soto (2002), considerando cómo se publicó inicialmente la novela, afirma que "el primer lector de El infierno verde no tenía los elementos de juicio necesarios para leer el texto como una novela o un producto literario; más bien, partiendo de los indicios que se le daban y de los criterios convencionales para determinar la autoría y el género de las publicaciones, debía considerarlo un reportaje periodístico o un testimonio histórico".

${ }^{5}$ Recordemos: el lunes 9 de marzo de 1914, el teniente Alejandro Bello Silva, nieto del erudito Andrés Bello, despega del aeródromo de Lo Espejo para hacer el recorrido Lo Espejo - Culitrín - Cartagena - Lo Espejo, en un lapso máximo de 48 horas, con la intención de obtener así el diploma chileno de aviador militar. Durante ese vuelo desapareció sin dejar rastro y su terrible peripecia se ha integrado al folklore chileno. 
con qué intención. La idea que se diseña de algo y que se transmite depende, pues, de un punto de vista; es decir, del lugar (geográfico o ideológico) desde el que se escribe ${ }^{6}$, dependiente, de una u otra forma, de la tradición.

Al hablar de tradición, siempre es bueno recordar aquel ensayo de Alejo Carpentier en el que, lúcidamente, explica que los árboles americanos, como la ceiba, "no tienen la ventura de llamarse pino, ni palmera, ni nogal, ni castaño, ni abedul. San Luis de Francia no se sentó a su sombra, ni Pushkin les ha dedicado uno u otro verso" (Carpentier, 1967: 35). Si incluimos la ceiba en un párrafo literario, necesitaremos describirla porque no está inserta en tradición literaria alguna. Claro que ninguna tradición es inocente ni aséptica.

Sabido es cómo los historiadores de Indias vieron la realidad desde el mundo caballeresco literario o bien, a la manera de Alvar Núñez Cabeza de Vaca, refiriéndolo a una suerte de obviedad ya vivida, aunque sólo fuese leída, como en el caso de la descripción de las cataratas de Iguazú: "Da el río un salto por unas peñas abajo muy altas, y da el agua en lo bajo de la tierra tan grande golpe que de muy lejos se oye; y la espuma del agua, como cae con tanta fuerza, sube en alto dos lanzas y más" (Núñez Cabeza de Vaca 1542, 166).

La conformación literaria moderna de la naturaleza americana parte en el siglo XIX, como es sabido, de unas narraciones del francés Chateaubriand: Atala [1801] y su continuación René [1805]. Muchos tópicos de la poesía llamada modernista fueron, así mismo, explorados antes por los parnasianos franceses. El antecedente factual de una obra literaria no puede buscarse sólo en una realidad que el espejo debiera reflejar, sino también -y de modo trascendente- en el tipo de espejo y en el modo aprendido de llevarlo: obviedades mostrencas, antecedentes simbólicos, míticos, tópicos, funcionales o estilísticos, según advertí antes. Como escribe el poeta dominicano Héctor Incháustegui Cabral, "un gran poeta suele ser el resultado, cuando se es realmente grande, de todos los que antes que él ejercieron la profesión y [...], niéguese o no, él será el resumen en grande de todo lo que antes que él hicieron sus antecesores en el tiempo" (1960: 172).

La novela de José Marín Cañas El infierno verde no toma su título de una experiencia personal primigenia, sino de una tradición literaria ya establecida. Sin duda entendemos que el autor se refiere a una naturaleza

${ }^{6}$ Trato de estos temas en Urrutia (1997). 
agresiva e incluso cruel, que es la selva americana la cual, para los lectores modernos, tuvo su retrato definitivo en La vorágine, de José Eustasio Rivera. En la memoria de todos están aquellos párrafos que abren la segunda parte de la novela:

¡Oh selva, esposa del silencio, madre de la soledad y de la neblina! ¿Qué hado maligno me dejó prisionero en tu cárcel verde? [...] Tú eres la catedral de la pesadumbre. [...] Déjame huir, oh selva, de tus enfermizas penumbras, formadas con el hálito de los seres que agonizaron en el abandono de tu majestad. iTú misma pareces un cementerio enorme donde te pudres y resucitas! (1924: 189 y 190).

Nada tiene esta selva que ver, como algún crítico despistado sostiene, con la de El libro de las tierras vírgenes [1894], de Rudyard Kipling, ni con la entrevista en El corazón de las tinieblas [1899] de Joseph Conrad, pero tampoco con el escenario teatral de Manuela [1858-1889], de Eugenio Díaz de Castro, o con la naturaleza acogedora de María [1867], de Jorge Isaacs.

Posiblemente el descubrimiento literario de la selva corresponde a los escritores brasileños. Desde Contos amazónicos [1893], de Inglês de Sousa, hasta Os Igaraúnas [1938], de Raimundo Morais, la literatura brasileña cuenta con, al menos, siete libros valiosos sobre la selva amazónica, en los que se entremezclan narraciones, ensayos, crónicas e, incluso, leyendas y ficción científica: O paroara [1899], de Rodolfo Teófilo; Terra imatura [1923], de Alfredo Ladislau; A Amazônia misteriosa [1925], de Gastão Cruls; Macunaíma [1928], de Mário de Andrade; y Os deserdados [1931], de Carlos de Vasconcelos 7 . Los brasileños tratarán también el tema de la plantación de cacao, como en la novela de ese título de Jorge Amado. A estas obras hay que añadir $A$ selva (1930), novela del portugués Ferreira de Castro (1898-1974), escrita a partir de una intensa experiencia brasileña. De hecho, el sintagma "infierno verde", que nombra la novela de José Marín Cañas y este trabajo mío, tiene un antecedente importante que no quiero olvidar. Es título de un libro publicado en 1908 por el brasileño Alberto Rangel (1871-1945), Inferno verde. Scenas e scenários do Amazonas (1908).

\footnotetext{
${ }^{7}$ Véase Pedro Maligo (1998).
} 
La importancia de la obra de Rangel radica en que para él la selva es un lugar corrupto de sufrimiento y muerte, imagen que se impondrá como significación estable en la literatura posterior. Sólo los hombres superiores pueden ser capaces de resistir sus embates y su $\operatorname{caos}^{8}$ porque, según hubiese escrito Joseph Conrad, “aquella tierra no parecía terrenal” (Conrad, XXXX: 124). Un relato de Mario Payeras (1940-1995), sobre la actuación de un grupo guerrillero en la selva guatemalteca, Los días de la selva, es un buen ejemplo de cómo la naturaleza es mucho más poderosa que la voluntad de los hombres. En diversos momentos el lector descubre la incapacidad de los guerrilleros: "La noche húmeda del trópico se llenaba de chillidos de pizotes, de toses de micoleones y de autocríticas de militantes. [...] La guerrilla de la sierra era un grupo de esqueletos que perseguía durante las horas de luz los pocos rayos de sol filtrados por el follaje" (Payeras, 1980: 30 y 128-129)․ El prologuista del libro de Rangel fue Euclides da Cunha (1866-1909), el autor de Os sertoes [1902], quien venía publicando artículos sobre la selva amazónica que se recogerían en el póstumo Á margen da história [1909]. Para Cunha esa geografía no respondía al infierno sino, por el contrario, al paraíso, un paraíso perdido o, al menos, no concluido porque la Amazonía "é a última página, ainda a escrever-se, do Gênese"

${ }^{8}$ De ahí surgirá más tarde la idea de que sólo los indígenas son capaces de integrarse en la selva. Un ejemplo puede ser la novela de Luis Sepúlveda Un viejo que leía novelas de amor (Barcelona: Tusquets, 1993). Véase la tesis de maestría de Claudia Cárdenas Sosa: Lectura de la selva: paisaje cerrado, recepción abierta; Universidad Nacional Autónoma de México (2011).

${ }^{9}$ En las páginas 70-71 se narra una escena tremenda con una conclusión terrorífica: "Nunca entendió esta gran enseñanza de la vida revolucionaria. [...] Quien había sido incapaz de sobreponerse a las privaciones del monte, seguramente sucumbiría también ante la tortura. Lo fusilamos en abril, una mañana en que cantaban muchos pájaros. Era el grato ruido del mundo que el condenado dejaría de oír en poco tiempo. Durante la reunión en que le anunciamos la pena, reaccionó abrumado, como si todavía no le diera crédito a lo que le comunicábamos. Luego, hizo desesperados esfuerzos por sustraerse a su suerte; prometió fidelidad y cuanta razón le aconsejó el amor a la vida. [...] Mientras caminaba hacia el lugar de la ejecución pidió todavía un trozo de panela que guardaba en la mochila. [...] En el momento supremo, muy pálido, desvió la mirada del pelotón de fusilamiento. Al volver a nuestros puestos, un silencio significativo se hizo en el campamento. Probablemente, a partir de entonces, todos fuimos mejores".

${ }^{10}$ Um paraíso perdido ha sido el título de una selección de artículos de Euclides da Cunha y de ensayos sobre él preparada por Hildon Rocha, publicada en 2002 por el Senado Federal, en la Coleção Brasil 500 anos, Brasilia. 
La selva, pues, más allá de la realidad geográfica, es una construcción literaria y ésta, incluso, puede influir sobre la apreciación de aquélla; así, la denominación peyorativa "infierno verde" acabó por usarse para denominar toda la dimensión de la región Norte del Brasil ${ }^{11}$. Podemos, pues, aceptar que la selva es un actante de este subgénero novelesco. Utilizo actante en el sentido que le da Algirdas Julien Greimas, una categoría semántica de carácter formal capaz de ser utilizada en otros objetos de análisis no estrictamente lingüísticos. O, como hubiera dicho Vladimir Propp, pueden cambiar los nombres y los atributos de los personajes, pero sus acciones o funciones se mantienen de un cuento a otro ${ }^{12}$. Así, la selva puede sustituirse por el desierto, por la sierra o la montaña, por el territorio desconocido, etc. Siempre será un territorio agreste, agresivo, duro para el hombre que irrumpe en él.

\section{Los yerbales}

Tanto el libro de Rangel como los trabajos de Cunha transitan entre la crónica y la ficción, cuando ésta parece preferible para concentrar la experiencia que pretende testimoniarse. El periodismo de denuncia ya se practicaba en América cuando los libros de uno y otro se editan. Artículos periodísticos constituyeron sin duda la inmensa mayoría de lo publicado por Rafael Barrett (1876-1910), autor a quien Augusto Roa Bastos (1917-2005) considera maestro de los mejores narradores y poetas del Paraguay (Roa Bastos, 2002: 243-265). El 15 de junio de 1908, desde las páginas de El Diario, de Asunción, el escritor hispano-paraguayo aseguraba necesario que el mundo supiese lo que sucedía en los yerbales. Se refería a las condiciones de trabajo existentes en Paraguay, Uruguay y el norte de la Argentina dentro de las plantaciones de los árboles con cuyas hojas se prepara el que un día se llamó "el té de los jesuitas”, el mate, esos yerbales que también cita de pasada José Marín Cañas.

Barrett, aquel español amigo de Pío Baroja o Ramón del Valle-Inclán, que había huido al sur de América escapado de una persecución judicial

${ }^{11}$ José Francisco da Silva Queiroz: "Amazônia: Inferno verde ou Paraíso perdido? Cenário e territorio na literatura escrita por Alberto Rangel e Euclides da Cunha”, p. 10. http://www.brasa.org/wordpress/wp-content/uploads/2015/07/Jos\%C3\%A9-Franciscoda-Silva-Queiroz.pdf

${ }^{12}$ Greimas (1966), Vladimir Propp (1924), Urrutia (2007: 63 y ss.). 
por haberse batido en duelo, y que se considera el fundador de la literatura paraguaya, desgranó durante la segunda quincena de aquel mes de junio de 1908 media docena de durísimos artículos de testimonio y denuncia, reunidos bajo el título Lo que son los yerbales. "Y a los que duden o desmientan les diré -escribe-: Venid conmigo a los yerbales y con vuestros ojos veréis la verdad".

Según Barrett, el trabajo se lleva a cabo en condiciones de extrema dureza. El obrero se interna en la selva. Allí encuentra

la milenaria capa de humus, bañada en la transpiración de la tierra; el monstruo inextricable, inmóvil, hecho de millones de plantas atadas en un solo nudo infinito; la húmeda soledad donde acecha la muerte y donde el horror gotea como en las grutas... iLa selva! La rama serpiente y la elástica zarpa y el devorar silencioso de los insectos invisibles (Barrett, 1988: 13).

En esa naturaleza invasora y cruel, "el hombre desaparece, sepultado bajo la codicia del hombre" (Barrett, 1988: 14) ${ }^{13}$. Tiene que desgajar la planta y acarrear un mínimo de ocho arrobas (9o kilos), durante el día. Por la noche,

alcanza el fogón, overea el ramaje, es decir, lo tuesta en la llama, abrasándose las manos; deshoja la rama destrozándose los dedos; pisa la hoja en el raído, sujetando con tiras de cuero la mole, que llevará a cuestas hasta el romanaje donde será pesada (Barrett, 1988: 14).

Continúa así describiendo los distintos trabajos ligados a la hierba mate y se pregunta: "Y esa gente ¿qué come? ¿De qué manera se la trata? ¿Qué salario se le abona y qué ganancia produce a los habilitados y a la empresa" (Barrett, 1988: 15). El salario es efectivamente miserable, pero lo más grave es que los obreros cobran una prima de enganche que, o bien suelen gastar inmediatamente, o bien envían a su familia y, a partir de ese momento, quedan en deuda con la empresa, pues en los yerbales no existe otro colmado donde comprar ropa, alimentos y herramientas que el de la organización, con los precios que ella marca, por lo que la deuda inicial resulta impagable.

${ }^{13}$ El crítico Roberto González Echevarría (1995) estima que si las novelas de la selva tienen un carácter subversivo, se debe precisamente a su preocupación por la descripción de lo bárbaro frente al mundo que consideraríamos "bien hecho". 
De ahí que, según explica Barrett, se desprenda un régimen de esclavitud y la fuga del trabajador se castigue con torturas y cárceles.

\section{Relato personal}

Permítanseme que haga una interrupción autobiográfica. El 15 de abril de 1968, a punto de terminar mi licenciatura universitaria, acudí con unos amigos a la romería del Cristo de La Almoraima, una de esas fiestas populares andaluzas en las que lo religioso es un pretexto más o menos consciente para pasar un día de fiesta, baile, comida campestre y bebida abundante.

Fuimos en un par de automóviles, aunque lo suyo hubiera sido haber ido a caballo, sobre todo si hubiésemos pensado en subir al pueblo, en la cima de la colina, dominado por un castillo de construcción árabe que permite la vista de un paisaje extraordinario de campiña, pequeñas alturas y mar brillante, junto al que descuella el peñón de Gibraltar. Para alcanzar el pueblo nos hubiera bastado con seguir por un par de horas la orilla accidentada del río Hozgarganta, cruzarlo luego por un bajo, y cabalgar hacia el suroeste hasta el pie de la colina. Ahí, buscaríamos uno de los senderos que el tiempo y la paciencia de los habitantes ha ido trazando entre la piedra, la maleza, los helechos y las chumberas, pues el calor y la pluviosidad de la zona hacen que se hermanen ambas plantas.

La finca de la Almoraima, en cuya barriada de la estación de ferrocarril se encuentran la casa solariega de administración y el convento donde radica el famoso Cristo, poseía entonces con 16.073 hectáreas en un término municipal, Castellar de la Frontera, que sólo contaba con unas mil hectáreas más. Constituía el mayor latifundio de España y uno de los mayores de Europa. Por entonces sólo el 15\% de la propiedad era cultivable y sólo el 1\% lo constituían tierras de regadío. Llegamos, como tanta gente de los pueblos limítrofes, a la zona de la romería. En la entrada de la finca la Guardia Civil nos impidió el paso, porque los directivos de la empresa habían prohibido llegar donde se custodia la imagen y, por lo tanto, impedían la celebración tradicional.

Joven llegado de la capital en plena efervescencia estudiantil, no podía sino sentirme escandalizado por un ejemplo más del autoritarismo que solía manifestarse en el país, pero que no comprendía que pudiese ser posible tan sólo por la fuerza de una de las llamadas grandes familias y de 
sus representantes. No había sido aquél el primer ni el único capricho del consejero-delegado de la finca. El primero de junio de 1962 le había dado veinticuatro horas de plazo a un trabajador que ejercía funciones de portero para que se afeitase el bigote "por razones de ética y buen gusto que rige en esta Empresa”. Ésta contaba en 1968, además de con los buenos oficios de la Guardia Civil, con dos docenas de hombres armados.

El pueblo de Castellar, incluidos los edificios del ayuntamiento o de la iglesia, era entero propiedad del Duque de Medinaceli. Carecía de agua corriente y de servicios sanitarios, incluso de pozos negros. Los habitantes tenían que salir de las antiguas murallas para hacer sus necesidades en el campo. La fuente más próxima obligaba a caminar dos kilómetros de pendiente y estaba muchas veces contaminada. Las viviendas también eran propiedad del ducado y, salvo las que están intramuros, pues se conservan las murallas medievales, no eran sino chozas con techo de paja de las que puede desahuciarse fácil, rápidamente y con toda legalidad a la familia que las habite.

Si el corcho, la más importante producción de La Almoraima, lo explotaba la sociedad creada al efecto, la otra fuente de ingreso era el carbón vegetal. Para hacerlo, los carboneros pedían permiso de extraer la leña, concediéndose a cada persona autorizada un espacio determinado de la finca en el cual le estaba permitido extraer la leña necesaria y proceder a la operación de elaborado del carbón. Concluidas estas tareas, se vendía el carbón ya listo a los intermediarios. Sólo se cerraba la venta cada seis meses, pagando una cantidad que oscilaba entre 4 y 6 pesetas por arroba (11,5 kilogramos). Se necesitaba un esfuerzo mancomunado de la familia para poder obtener unas 405 arrobas diarias en situación normal, pudiendo llegarse a un máximo de $7 \mathrm{u} 8$ arrobas diarias en el caso de trabajar desde el amanecer hasta las dos de la madrugada. El colmado del pueblo suministraba garbanzos, tocino, azúcar y café. Al final se hacía una liquidación descontando de la paga el valor de lo consumido al precio marcado por la empresa, con lo cual ambas partidas daban casi siempre un saldo negativo para el trabajador. Con el transcurso del tiempo se iba transformando en un endeudamiento del que era prácticamente imposible salir ${ }^{14}$.

${ }^{14}$ Véase Juan Maestre (1968: 98-99). 
Fue, por lo tanto, al finalizar mis estudios universitarios cuando conocí directamente una relación capital/trabajo que venía a ser versión moderna de la esclavitud. Los trabajadores, aparentemente libres y autónomos, se veían atados a una empresa agrícola por las deudas contraídas anteriormente con la misma, ya que les resultaba imposible proveerse de alimentos, vestido, alojamiento y herramientas fuera de la finca y a precios distintos de los fijados por unos encargados de la empresa. Si algún obrero tomaba la decisión de marcharse y conseguía burlar la vigilancia, la Guardia Civil lo detenía por las deudas contraídas.

Entre los libros de mi padre, el 29 de mayo de 1971, según tengo anotado, cayó en mis manos Juan Pérez Jolote. Biografía de un tzotzil, un apasionante libro de Ricardo Pozas. Nunca había yo leído de forma tan clara lo que es el mestizaje cultural, la resistencia del pensamiento indígena en la sociedad americana y la acomodación del ser humano a las situaciones más duras de trato y vida. Hubo un aspecto del libro de Pozas que me llamó especialmente la atención, desde el prólogo. Explica la relación laboral y económica de los tzotziles con las fincas cafeteras de los distritos de Soconusco y de Mariscala, en México:

Son contratados mediante el sistema de "enganche", que consiste en adelantar al trabajador una cantidad de dinero, para asegurarlo y obligarlo a acudir a las fincas; sistema que se presta a negocios turbios en los que el indio es objeto de robo y otros abusos, sin que por esto deje de ser la fuente principal con que completan su economía, pues aseguran con tales ingresos los gastos que requieren el conseguir mujer y las relaciones con las instituciones y los hombres de su propia cultura (Pozas, 1968 [1952]: 10).

La prima de enganche no podía menos que recordarme, más allá del mayor o menor esfuerzo que el trabajo en los cafetales signifique frente a la elaboración del carbón vegetal, la entrega de mercancías varias con que se recibía en La Almoraima al nuevo carbonero. Un sistema económico y laboral, en ambos casos, que implica la dependencia absoluta del trabajador con respecto al patrono hasta que no salde la totalidad de la deuda, cosa a veces prácticamente imposible.

¿Sería este procedimiento de contratación con vocación esclavista una exportación de España a América? No dejo de recordar cómo el expresidente dominicano Juan Bosch, en su libro indispensable para entender la socie- 
dad caribeña Composición social dominicana (1970), deja entrever cómo la relación capital/trabajo que los españoles impusieron en América no era sino la que los conquistadores habían conocido (¿y sufrido?) en los cortijos extremeños y andaluces.

\section{La novela de los yerbales}

La narración La Caa Yarí. Novela de los yerbales misioneros (1945), del argentino Alejandro Magrassi (1899-1991), describe el acto de enganche de un mensú o trabajador de los yerbales. El reclutador le invita a unas cuantas copas y le ofrece cuarenta pesos; cuando acepta, saca del bolsillo un papel impreso con el membrete de la finca y extiende un recibo que el contratado firmará con la huella digital y que dice:

Itatí (Corrientes), 13 de mayo de 1939. Por la presente reconozco al señor Franz Elsten, la suma de cuarenta pesos, cuya cantidad me comprometo a canjear con mis trabajos en el establecimiento de La Matera, en Alto Grande, Misiones.

El novelista advierte que Viriato Medina, el protagonista, una vez gastado todo el dinero recibido en el mismo colmado donde firmó el enganche, "estaba contentísimo, sin saber que había cambiado la casa en que vivía por los peligros de la selva, la seguridad de una vida tranquila por una existencia miserable e infernal" (Magrassi, 1945: 9 y 13). Roa Bastos, en su cuento "Los mensú”, incluido en El trueno entre las hojas [1953], insiste en que estos trabajadores sólo poseen "un desprendimiento brutal de su dinero" y el personaje de su relato, después de sufrir todas las miserias y todos los dolores, a los diez minutos de haber conseguido liberarse de los compromisos, "estaba ya borracho, con nueva contrata, y se encaminaba tambaleando a comprar extractos". No puedo detenerme en los cuentos de Roa porque se escapan ya del período que intento acotar y que cierro con el abandono de la narración plenamente realista que significa la trilogía de Miguel Ángel Asturias (1899-1974) compuesta por Viento fuerte [1950], El papa verde [1954)] y la tardía Los ojos de los enterrados [1960]. La literatura, en cualquier caso, trae a mi presente aquellas experiencias de mi pasado. Incluso despierta en 
mí, lector, la rabia de una juventud que buscaba discernir si la verdad estaba en la visión parcial que yo tenía de la carretera y del pueblo aquel, o en la literatura de ficción que logra trascender la anécdota y, a través de ella, fuera el escritor protagonista o no de los hechos, producir el efecto de testimonio.

No sabría decir si el progreso consiste en cambiar los collares a los perros y nunca en suprimirlos, pero el ser humano es el único animal capaz de inventar modos y formas de mancillar y hacer daño a sus semejantes. La literatura no pudo quedar ajena a realidades tan hirientes y los novelistas americanos que se han situado frente a los territorios de plantación, tanto de mate, como de café, arroz, banano, cacao, tabaco, caña de azúcar han buscado cómo describirlas, dando pie a un subgénero peculiar ${ }^{15}$. Y no olvidemos las novelas del caucho, generalmente situadas en la zona fronteriza del Putumayo, cuyo modelo es A selva [1930], del portugués Ferreira de Castro, a la que hay que sumar Toá [1933], del colombiano César Uribe Piedrahita. Ambas han dejado su huella en la segunda parte de El sueño del celta [2010)], de Mario Vargas Llosa.

En A selva, un fuego final purificador cierra la aventura y una tortura infernal; la novela se convertirá en modelo que todos los que rocen literariamente el Putumayo y su catálogo de atrocidades, ya establecido el informe conocido como El libro rojo del Putumayo publicado, primeramente en inglés, al principio del segundo decenio del siglo XX y, en 1913.

Rafael Barrett, en sus artículos sobre los yerbales, proporcionaba a la novela posterior los elementos argumentales para ese tipo de novela. Cambiarán los productos agrarios que se trabajan, pero las condiciones sociales apenas varían. En las narraciones que tratan de los campos de café (como La cosecha [1935], del colombiano Osorio Lizarazo; Solar Montoya [1940], del puertorriqueño Enrique Laguerre, o Gentes y gentecillas [1947], del costarricense Carlos Luis Fallas), o de arroz (así Nuestro pan, 1942)], del ecuatoriano Enrique Gil Gilbert), la selva no existe o no influye, pero generalmente suele ser el marco decisivo de la acción y no resulta un espacio acogedor ni paradisiaco. Es el caso de la preocupación por el estado de los manglares (como en Don Goyo [1933], del ecuatoriano Demetrio Aguilera

${ }^{15}$ Publiqué hace tiempo dos artículos sobre este tema que hoy reconozco insuficientes y necesitados de una revisión: Urrutia (2011a y 2011b). 
Malta), del racismo y el cultivo de la tagua (Yuyungo [1942], de Adalberto Ortiz, también ecuatoriano) o del tabaco (Los dedos de la mano, [1951], de Laguerre). Pero, sobre todo, abundan las novelas sobre el trabajo en los campos bananeros, desde los cuentos de la costarricense Carmen Lyra, Bananos $y$ hombres [1931], hasta la trilogía de Miguel Ángel Asturias, en Guatemala ${ }^{16}$. También hay una importante serie sobre el trabajo en los campos de caña de azúcar, desde Ecue-Yamba-O, de Alejo Carpentier [1933], hasta, dentro del período que me interesa, El sitio de las abras [1950], del costarricense Fabián Dobles ${ }^{17}$.

Estamos ante el entorno insumiso en el que se desenvuelven los trabajadores de la América Central, incluidas las Antillas, y del Sur, aunque no debe desecharse la paralela producción obrera norteamericana de ambiente rural, que puede representar John Steinbeck con su novela Las uvas de la ira [1939]. Una geografía y una sociedad que el escritor debe, como el explorador, desbrozar, y como el fundador de ciudades, ordenar y someter a una retórica. Pese a su americanismo, estamos lejos del Mundonovismo que teorizó Francisco Contreras (1877-1933) en el prólogo a El pueblo maravilloso (1927), porque no hay subconciencia, sino condiciones materiales de vida, aunque en algunos casos podamos encontrar referencias míticas y misteriosas. Contreras, ese Jules Romains de la campiña, se aproxima del Unanimismo cuando asegura que los novelistas deben proponerse "interpretar la humanidad integralmente", tratando de destacar "todo el inmenso e inquietante universo humano" (Contreras, 1927: 20). Romains, por su parte, entendía que era necesario transponer el análisis psicológico, hasta entonces reservado a los individuos, a un ser colectivo ${ }^{18}$.

${ }^{16}$ Pasando, al menos, por Crisol [1937], de José Isaac Fábrega, Panamá; Mamita Yunai [1941], la única de estas novelas que se cita, sin que sea la mejor, en absoluto, de Carlos Luis Fallas, Costa Rica; Bananos [1942], del ecuatoriano Emilio Quintana; Cosmapa [1944], de José Román, Nicaragua; Prisión verde [1950], de Amaya Amador, Honduras; o Puerto Limón [1950], de Joaquín Gutiérrez, Costa Rica.

${ }^{17}$ Serie en la que hay que contar con otras novelas: La llamarada [1935], del puertorriqueño Laguerre; San Cristóbal [1947], de Ramón H. Jurado, Panamá; o las novelas dominicanas Cañas y bueyes [1936], de José Moscoso Pueyo; Los enemigos de la tierra, del mismo año, de Andrés Requen; Over [1939], de Ramón Marrero Aristy, y Jenjibre [1939], de Pedro A. Pérez Cabral.

${ }^{18}$ Véase el prefacio de Michel Décaudin a La vie unanime, de Jules Romains. 
Pero en los años veinte, treinta y cuarenta del siglo XX, se hace necesaria la adaptación, teórica y práctica, de la literatura social, paraproletaria y proletaria que, desde los planteamientos de un nuevo realismo, se difunde desde Europa, especialmente tras la experiencia de la Primera Gran Guerra y, más tarde, de los acuerdos del famoso congreso soviético de Jarkóv (Congreso de la Asociación Rusa de Escritores Proletarios), en noviembre de 1930, y la creación de la Unión Internacional de Escritores Revolucionarios (Urrutia, 2012). La orientación política de la mayor parte de la literatura explica que también puedan aparecer obras sobre las plantaciones o el trabajo rural escritas desde el punto de vista contario, en este caso el del patrono. Es el caso de José María Albiñana Sanz, el doctor Albiñana, autor de Aventuras tropicales. En busca del oro verde (1928), quien describe a los trabajadores de la bananera de forma despreciativa:

Los había de diferentes cataduras, todas terribles y alarmantes: pigmeos de anchas espaldas y rostro plano; gigantones cenceños y tristes, con el pistolón oculto en el cinto y el largo machete recientemente afilado. [...] Casi todos eran desecho de los campos petroleros extendidos en las márgenes de los ríos Uspanapa y Coatzacoalcos; gentes peligrosas que los capataces habían dado de baja por camorristas y viciosos. Muchos exhibían en todo el cuerpo amplios tatuajes azulados representando las más extrañas y opuestas figuras: imágenes de santos, cruces misteriosas, lagartos, perros, jeroglíficos (Albiñana Sanz, 1928: 340).

Dos años antes de que Alejandro Magrassi publicara La Cáa Yarí, Alfredo Varela (1914-1984) había dado a conocer la gran novela argentina sobre los yerbales: El río oscuro. A través de una narración fragmentaria, se pliega más a la vida y el trabajo de los obreros. Es necesaria la fragmentación porque, como decían Erckmann y Chatrian, el testigo no conoce sino una parte de lo sucedido. Varela insiste en la escasa legalidad de los contratos, en el engaño generalizado, en la crueldad de los capataces, en la explotación, en las durísimas condiciones de trabajo. La novela se abre a todo tipo de personajes. En ocasiones, la prosa tiende hacia la lírica, como si la belleza del estilo pudiera hacer más llevadero el relato de la injusticia. Queda el lector dudando si la dureza de esa vida está motivada por las dificultades del trabajo o por la crueldad de la selva que lo penetra todo. Vida y muerte 
se unen irremediablemente a través del río Paraná, que lleva a los hombres ilusionados y los devuelve hechos cadáveres flotantes.

Un día veían partir un barco repleto de mensús. Y luego, algún día o alguna noche, llegaba un cadáver, boyando. Y después otro, y otro más. Venían tranquilos, y varaban en la playa pedregosa, al pie de la lomita. Por eso, cuando alguien se embarcaba para el Alto Paraná, se lo despedía definitivamente. Volver, volvería quizá. Pero solo, inerte, con unas tiras de ropa sobre el cuerpo golpeado. Entones, la despedida se hacía con mucha caña, para no pensar en lo que ha de ocurrir.

Pero el novelista quiere creer que hubo un tiempo en que los yerbales no producían muerte, sino vida. Era un mundo mítico que (sobre todo Magrassi) los novelistas explotan. Leemos en el libro de Varela:

Antes fue un hermoso tiempo de ignorancia. Los salvajes eran dueños de una felicidad clara y espontánea. Fue cuando la hierba mate era amiga de los hombres. Una de las humanísimas divinidades celestes les enseñó cómo tostar y usar la deliciosa cáa. [...] De pronto se sublevaron los océanos, salieron de madre los ríos, y el cielo relampagueante anunció males terribles. Aparecieron los conquistadores blancos, Y desde entonces, donde quiera que surgían las resistentes hojas verde-oscuras, trajeron consigo la desgracia, el abuso, la esclavitud (Varela, 1943: 19 y 33).

La explotación de la tierra es paralela a la explotación del ser humano. No puedo dejar de recordar aquí cómo Joseph Conrad, en El corazón de las tinieblas, decía que la conquista de la tierra no suele consistir sino "en arrebatársela a aquellos que tienen una piel distinta o la nariz ligeramente más achatada que nosotros" $(1899,82)$.

Las novelas de Magrassi y de Varela, en su dureza, siguen la senda abierta en la literatura argentina por algunos de los Cuentos de amor de locura y de muerte [1917], de Horacio Quiroga (1878-1937), que fue incluso propietario de un yerbal. De ese modo, el subgénero narrativo que busco delimitar se inicia en el realismo periodístico, se empapa del irracionalismo de Quiroga y termina en lo que se ha venido en llamar el realismo mágico, cuando Miguel Ángel Asturias rompe definitivamente con la prosa exclusivamente referencial. 


\section{La veracidad de la literatura}

Mario Vargas Llosa comenta, en su tesis doctoral, García Márquez: historia de un deicidio, la riqueza de Arataca, ciudad natal del novelista colombiano, cuando su economía tenía origen bananero. Observa que "lo que ocurre en la costa atlántica [de Colombia] con el banano, ocurre en otros lugares con la caña de azúcar, el algodón, el café, el petróleo".

Podemos también, sin duda, relacionar las novelas de plantación con otras que tratan de la minería, el petróleo o, incluso, la pampa salitrera (Moretić, 1962), si nos limitamos a las duras condiciones de trabajo. Cuando Jack London comenta la jungla (1906), de Upton Sinclair, afirma que se convertiría en La cabaña del Tío Tom del sistema asalariado (Malfi, 1981: 9). Y es que las condiciones del esclavo o las del obrero no parecen distanciarse mucho. Según London, el modelo narrativo que se establece para la narrativa de plantación es el fijado en la novela antiesclavista. Precisamente lo que nos ha interesado aquí es el procedimiento narrativo (sin duda heredado y transformado en gran parte de otras prácticas literarias), la coincidencia entre las novelas de una teórica realidad y unos modos de narrar.

Como se sabe, las dificultades económicas de la zona bananera colombiana que presionaron a los trabajadores dieron lugar el año 1928 a una importante huelga, reprimida por el ejército. La casa grande [1962], de Álvaro Cepeda Samudio (1926-1972), y un capítulo de Cien años de soledad [1967] narran los hechos y hablan de varios miles de muertos, cantidad sin duda muy exagerada según los historiadores. Gabriel García Márquez (1927-2014), en conversación con Mario Vargas Llosa, observa que la fantasía popular deformaba la verdad histórica. Por eso, el novelista peruano comenta: "A falta de algo mejor, Arataca vivía de mitos, de fantasmas, de soledad y de nostalgia. Casi toda la obra de García Márquez está elaborada con esos materiales que fueron el alimento de su infancia”. En nota a pie de página observa también que no es seguro que algunas anécdotas que cuenta en Cien años de soledad, como la de los excusados portátiles o los comprimidos usados por los niños como fichas en sus juegos, fueran verdades o bien invenciones novelescas que el autor repite como certezas. La conclusión está un par de páginas más atrás de García Márquez: historia de un deicidio. Dice Mario Vargas Llosa: 
Desde el punto de vista de las fuentes de un escritor, importa poco determinar la exactitud de [las] anécdotas, las dosis de verdad y de mentira que contienen. Más importante que saber cómo ocurrieron esos hechos [...] es averiguar cómo sobrevivieron en la memoria colectiva y cómo los recibió y creyó (o reinventó) el propio escritor Vargas Llosa, 1971: 16).

Aquí está resumida la función del estudio literario, porque la literatura no está para contar una verdad, sino para ser verdad ella misma y, así, conformar el mundo sintético de palabras con el que el lector pueda situarse. La novela de plantación (basándose sin duda en relatos orales de experiencias personales, en crónicas periodísticas, en texto oficiales e, incluso en documentos) crea una realidad que busca ser convincente y políticamente activa, cierta en parte desde el punto de vista histórico, pero también falsa. Construye una veracidad que insiste en el mito americano más permanente, el de sus venas abiertas.

\section{Referencias}

Albiñana Sanz, J. M. (1928). Aventuras tropicales. En busca del oro verde. Madrid: Espasa Calpe.

Rafael Barrett, R. (1988). Obras completas (edición de Miguel Ángel Fernández y Francisco Corral), Tomo II. Asunción: RP ediciones / Instituto de Cooperación Iberoamericana.

Bosch, J. (2005 [1970]). Composición social dominicana. Santo Domingo: Alfa \& Omega.

Carpentier, A. (1967). Tientos y diferencias. Montevideo: Arca.

Collazos, Ó., Cortázar, J. y Vargas Llosa, M. (1970). Literatura en la revolución y revolución en la literatura. México: Siglo XXI.

Conrad, J. (2008 [1899]). El corazón de las tiniebla, en Los libros de Marlow (Juventud. El corazón de las tinieblas. Lord Jim. Azar). Barcelona: Edhasa.

Contreras, F. (2007 [1927]). El pueblo maravilloso. Santiago de Chile: Biblioteca Nacional-Archivo del Escritor.

Erckmann-Chatrian (1950 [1865]). Waterloo. Madrid: Espasa Calpe (Austral). González Echeverría, R. (1995) "Canaima y los libros de la selva”; en Casa de las Américas 201. La Habana, pp. 22-31.

Greimas, A.-J. (1966). Sémantique structurale. Paris: Larousse.

Incháustegui Cabral, H. (1960). El pozo muerto. Santo Domingo: Universidad Católica Madre y Maestra. 
Maestre, J. (1968). Hombre, tierra y dependencia en el Campo de Gibraltar. Madrid: Cuadernos de Ciencia Nueva.

Magrassi, A. (1945). La Caa Yarí. Buenos Aires: Losada.

Malfi, M. (1981). La giungla e il gratacielo. Scrittori, lote di clase, "sogno americano", 1865-1920. Bologna: Odoya.

Maligo, P. (1998). Land of Metaphorical Desires. The Representation of Amazonia in Brazilian Literature. New York: Peter Lang.

Marín Cañas, J. (1935). El infierno verde (la guerra del Chaco). Madrid: Espasa Calpe.

Moretić, Y. (1962). El relato de la pampa salitrera. Santiago de Chile: Ediciones del Litoral.

Norton Cru, J. (1929). Témoins: essai d'analyse et de critique des souvenirs de combattants édités en français de 1915 à 1928. Paris: Les étincelles. . (2008 [1930]). Du témoignage. Paris: Allia.

N. T. (1913). El libro rojo del Putumayo. Bogotá: Arboleda \& Valencia.

Núñez Cabeza de Vaca, A. (1969 [1542]). Naufragios y comentarios (prólogo de Dionisio Ridruejo). Madrid: Taurus.

Payeras, M. (1980 [1998]). Los días de la selva. San Salvador: Piedra Santa.

Pozas A., R. (1968 [1952]). Juan Pérez Jolote. Biografía de un tzotzil. México: Fondo de Cultura Económica (6 $\left.{ }^{\mathrm{a}}\right)$.

Propp, V. (1971 [1928]). Morfología del cuento. Madrid: Fundamentos.

Quesada Soto, Á. (2002). Unos y los otros. Identidad y literatura en Costa Rica 1890-1940; San José: Universidad de Costa Rica.

(2008): Breve historia de la literatura costarricense. San José: Editorial Costa Rica.

Rivera, J. E. (1990 [1924]). La vorágine (ed. de Montserrat Ordóñez). Madrid: Cátedra.

Roa Bastos, A. (2002). Rafael Barrett, descubridor de la realidad social del Paraguay. Actual investigación, 51-52. Mérida: Universidad de los AndesVenezuela.

Romains, J. (1983 [1908]). La vie unánime. Paris: Gallimard.

Sarlo, B. (2013). Tiempo pasado. Cultura de la memoria y giro subjetivo. Una discusión. Talca, Chile: Universidad de Talca.

Urrutia, J. (1997). La verdad convenida. Literatura y comunicación. Madrid: Biblioteca Nueva. . (2007). El teatro como sistema. Madrid: Biblioteca Nueva. . (2011a). Testimonio y ficción. La novela frutera americana. Boletín de la Academia Dominicana de la Lengua $\mathrm{n}^{0}$ 25, Santo Domingo, 65/82. . (2011b). Acercamiento a un subgénero de la narrativa iberoamericana: la novela frutera. Miríada Hispánica $\mathrm{n}^{0} 2$. Valencia: University of VirginiaValencia, 75-101. . (2012). Revolución, elitismo y compromiso en el entorno de 1930, en 
AA.VV., 90 años de cultura en el Centro de Enseñanza para Extranjeros (265-288). México: Universidad Nacional Autónoma de México.

. (2015). Juguetes de un dios frío. Literatura, historia e ideología. Madrid: Devenir.

Varela, A. (s/f [1943]). El río oscuro. Buenos Aires: Agepe, S.A.

Vargas Llosa, M. (1967). García Márquez: historia de un deicidio. Barcelona: Barral.

Vichard de Saint-Réal, C. (1683). Conjurations des espagnols contre la république de Venise en l'année MDCXVIII. Paris: Chez Claude Barbin.

Wieviorka, A. (1998). L'ère du témoin. Paris: Plon. 